\title{
Disseminated Tuberculosis with Involvement of Appendix, Peritoneum and Right Knee Joint - A Case Report
}

\author{
MOHAMMAD SYEDUL ISLAM, ${ }^{1}$ MD. ABUL KALAM AZAD, ${ }^{2}$ HANIF MOHAMMAD, ${ }^{3}$ MOHAMMAD MUSHAHIDUL ISLAM, ${ }^{4}$ \\ MD. ABDUR RAHIM 5
}

\begin{abstract}
A 27 year old male presented with painful swelling of right knee joint for the last 6 months. Initially it was diagnosed as a case of reactive arthritis and was treated with NSAID with intraarticular steroids without significant improvement. Two months after the initial episode he again developed painful swelling of the right knee joint with severe abdominal pain and high grade fever. There was an ill defined ovoid mass in the right iliac fossa with generalized tenderness. ESR was raised and the ultrasonography revealed loculated ascites with appendicular lump. CT scan of the whole abdomen showed appendicular lump. FNAC from the lump showed tuberculosis. Joint fluid aspiration showed neutrophilic leucocytosis with the Total count $50,000 / \mathrm{cmm}$. AFB was not found. So septic arthritis was diagnosed, but as the patient was not improving we send the patient to orthopedic department for synovial biopsy but they refused as it was septic. So a diagnosis of disseminated Tuberculosis was made with the involvement of right knee joint, appendix and peritoneum. He was put on anti TB and well responded.
\end{abstract}

Key Words: Disseminated Tuberculosis, Appendicular lump, Arthritis.

\section{Introduction}

Tuberculosis presents with varied clinical manifestations as pulmonary or extra pulmonary tuberculosis. Extra pulmonary tuberculosis accounts for almost $15 \%$ of all cases of tuberculosis. ${ }^{1}$ Because of a substantial number of patients present with few or atypical symptoms, which mostly, but not exclusively present in immuno-compromised patients, the recognition of TB remains challenging. ${ }^{2}$ The time between the presentation of symptoms and diagnosis may turn out excessively long. For this varied presentation it is sometimes difficult to diagnose a case of extrapulmonary tuberculosis. Here we are reporting a case of tubercular appendicular lump, peritonitis with tubercular arthritis. This form of tuberculosis is seen as a part of disseminated tuberculosis.

\section{Case report}

A 27-year-old male presented with the complaints of pain and swelling in the right knee joint (fig: 1) for the last 6 months. On that occasion, his ESR was $42 \mathrm{~mm}$ in $1^{\text {st }}$ hour

1. Research Assistant, Department of Medicine, Bangabandhu Sheikh Mujib Medical University (BSMMU), Shahbag, Dhaka, Bangladesh.

2. Associate Professor, Department of Medicine, BSMMU, Dhaka

3. Associate Professor, Department of Medicine, MMC

4. Junior Consultant Medicine, MMCH.

5. Professor, Department of Medicine, BSMMU.

Correspondence : Dr. Mohammad Syedul Islam, Research Assistant, Department of Medicine, Bangabandhu Sheikh Mujib Medical University (BSMMU), Shahbag, Dhaka, Bangladesh. with normal differential count. Serum uric acid, Rheumatoid factor test, urine R/M/E, X-ray lumbosacral joint, Sacro-illiac joint, right knee joint was normal. He had no history of unsafe sexual exposure. He was diagnosed as a case of reactive arthritis and was treated with NSAID's and intra- articular steroid injection without significant improvement. Two months after the initial episode again he developed arthritis of same joint compelled him to be bed bound and walk with assistance. In both episodes there was no history of trauma, diarrhoea, dysuria, or any low back pain. Two months later he became febrile with abdominal pain, highest recorded temperature was $104^{0} \mathrm{~F}$. At that time he received several antibiotics with adequate dose and duration without any improvement. With that he was admitted in BSMMU in the department of medicine.

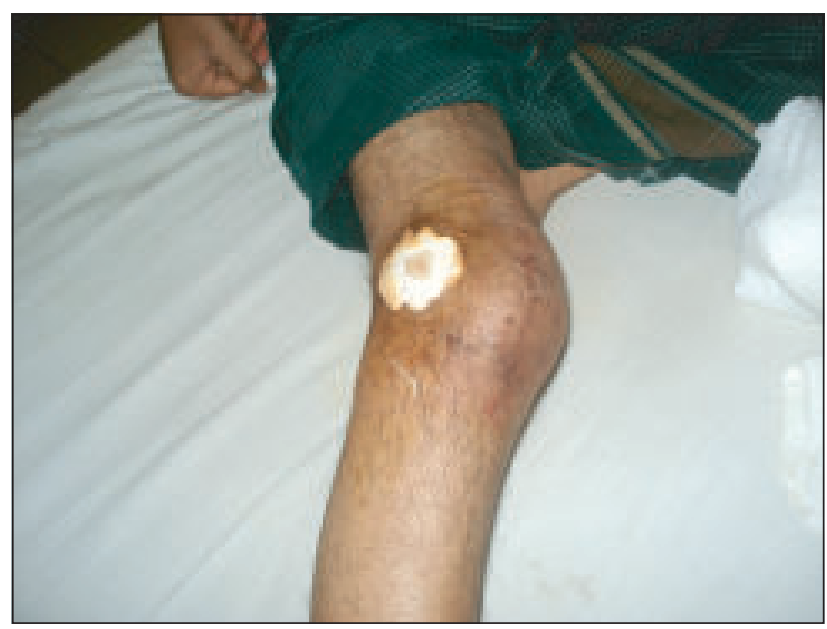

Fig.-1: Swelling of right knee joint 


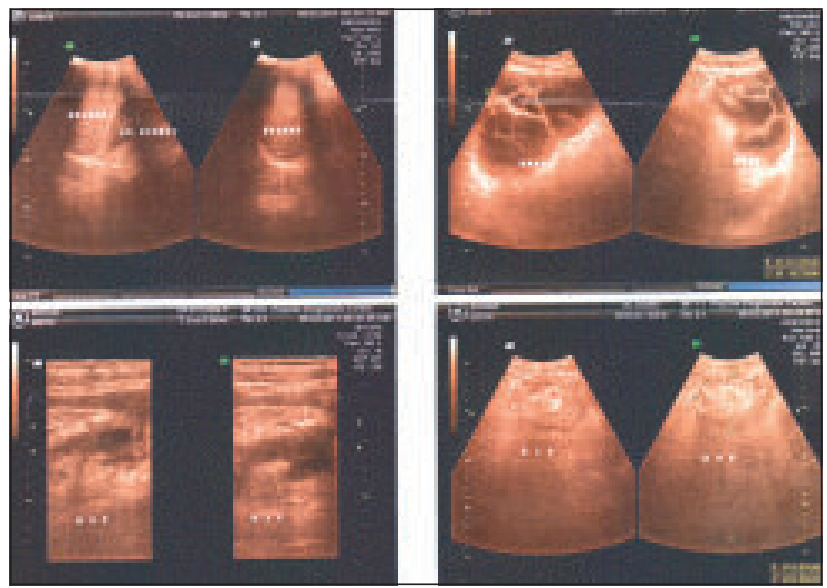

Fig.-2: Ultrasonography

On examination there was a lump in the right iliac fossa and another ovoid mass in the central abdomen. His $\mathrm{Hb}$ was 11.3 gm/dl, ESR: $66 \mathrm{~mm}$ in $1^{\text {st }}$ hour, normal leukocyte count. PBF showed microcytic hypochromic anaemia. Blood and urine $\mathrm{C} / \mathrm{S}$ were normal. Tuberculin test was $4 \mathrm{~mm}$. Chest skiagram, and X-ray of right knee joint normal. S creatinine was $0.9 \mathrm{mg}$ $/ \mathrm{dl}$, s uric acid $5.2 \mathrm{mg} / \mathrm{dl}, \mathrm{CRP} 12$, Rheumatoid factor negative. Ultrasonography showed loculated ascites, appendicular lump with a cystic mass around the umbilicus (fig. 2). CT scan of the whole abdomen showed appendicular lump with loculated ascites (fig 3,4). As the patient had knee arthritis for the last 6 months with no improvement with conventional approach, we had high degree of clinical suspicion of tubercular monoarthritis with appendicular and peritoneal tuberculosis. So we underwent, USG guided fine needle aspiration cytology was done from the appendicular lump. Smear shows moderate cellular material containing lymphocytes, histiocytes, a few giant cells, a few epitheloid cells and reactive mesothilial cells which are suggestive of tubercular granulomatous lesion. The right knee joint was swollen, tender and there was joint effusion. Synovial fluid study showed WBC- 50,000 cells/cu mm and neutrophils $95 \%$, pus cell absent, Z-n stain: AFB not found. Synovial fluid glucose and protein levels were not measured. So we referred the case to orthopedics department for synovial biopsy to establish tubercular arthritis. But due to septic arthritis they refused to do the biopsy.

With the above scenario he was diagnosed as a case of disseminated tuberculosis with involvement of appendix, peritoneum, and right knee joint with secondary septic arthritis. So, he was put on category-1 anti tuberculous therapy, and I/V flucloxacillin for adequate dose and duration with immobilization of the joint. He was discharged with significant improvement with continuation of the drugs.

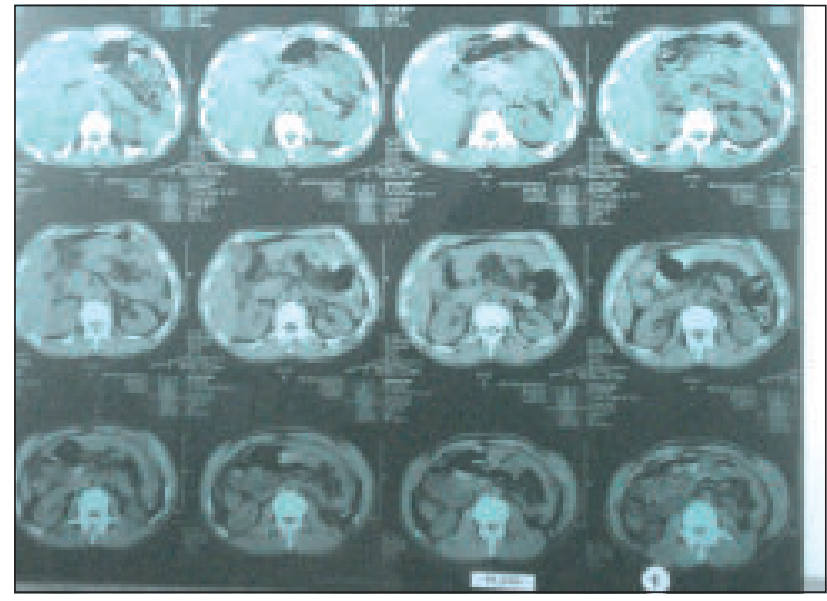

Fig.-3: CT scan of abdomen

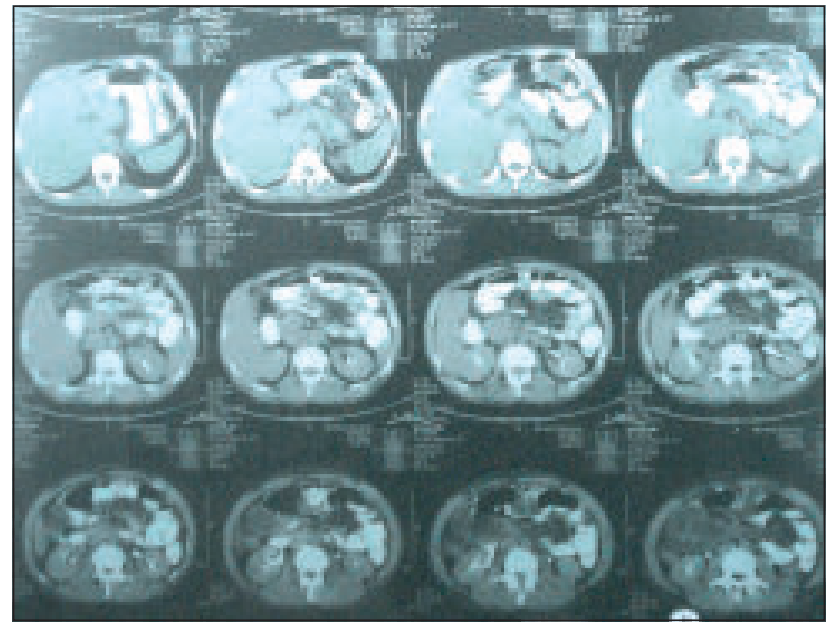

Fig.-4: CT scan of abdomen

\section{Discussion}

Tuberculosis (TB) is endemic in Bangladesh for long time. Emergence of multi drug resistant (MDR-TB) has added to the momentum of the disease in many countries including ours. It may affect primarily all organs and tissues of the body, although some of these show high immunity against the infection. ${ }^{1,3}$ The most common forms of non-pulmonary tuberculosis are tuberculosis of lymph nodes, pleura, peritoneum, alimentary system, bones and joints, cerebrospinal meninges, urinary system, sexual organs. The commonest presentation of abdominal tuberculosis is ileocecal disease, but isolated appendicular involvement is also rarely seen, occurring in only $0.1-0.6 \%$ of cases in the absence of pulmonary or other abdominal involvement. Three clinical types of tuberculous appendicitis have been described in literature. The first type presents as an acute form indistinguishable from pyogenic appendicitis until histologically proven. The second clinical type is a chronic form presenting with vague pain, occasional history of 
vomiting, diarrhoea and a mass in right iliac fossa. These cases are indistinguishable from cases of ileocaecal tuberculosis. The third type is a latent one found accidentally on histopathological examination. ${ }^{3,4}$ Our case appears to be of the second clinical type. Isolated tuberculosis of appendix may or may not be associated with specific clinical features, and diagnosis is often made only after histopathological examination. Therefore, it is strongly stressed that all surgically removed appendices should be sent for histopathological examination to exclude tuberculosis. Tuberculous appendicular lump is very rare now-a days due to early surgical intervention. ${ }^{5}$ It's commonly seen in young adults. It commonly presents with abdominal mass. Sometimes it becomes difficult early to diagnose. But if the diagnosis is early the treatment response is very good. ${ }^{6}$ Osteoarticular tuberculosis has also become very rare in western countries, but it is still a common problem in under developing countries. ${ }^{7}$ After the spine, the hip and the knee joint are the most common site of involvement for tuberculosis, and constitute approximately $15 \%$ of all cases of osteoarticular tuberculosis. ${ }^{8}$ The common age of presentation is in the second and third decades. A progressive pattern of destruction of the knee occurs in patients who are not treated. Treatment including drainage of collections, and antituberculous drugs must be instituted early with an aim of salvaging the knee. ${ }^{9}$ Like observed in our patient, the earliest manifestation of tuberculous arthritis is pain, which precede signs of inflammation for months and occasionally years. Imaging studies initially may show soft tissue swelling but later demonstrate osteopenia, periosteal thickening, periarticular bony destruction, and progressive destruction of cartilage and bone. ${ }^{10}$ If the patient is not treated, cold abscesses and draining sinuses often develop.

\section{Conclusion:}

Tubercular appendicular lump is very rare form of tuberculosis which is predominant in younger age group. Tuberculous arthritis is also rare presentation of extra pulmonary tuberculosis. It commonly affects the large joints, particularly the knee. So, a patient with monoarthritis without proper evaluation intra-articular injection of steroids should not be instituted. It could be devastating.

\section{Conflict of interest: None.}

\section{References:}

1. Ahasan HAMN, Hossain MA. Drug defaulters in pulmonary tuberculosis. Specialist 1997; 15: 175-9.

2. Andres SG, Tan-alora A. A case series of disseminated tuberculosis. Phil j microbial infect dis 2001; 30(1): 29-35.

3. Fanning A. Tuberculosis: 6. Extrapulmonary disease. CMAJ 1999; 160: 1597-603.

4. Linares LF, Valcarel A, Mesa Del Castillo J. Tuberculous arthritis with multiple joint involvement. J Rheumatol. 1991; 18: 635-636.

5. Watts HG, Lifeso RM. Tuberculosis of bones and joints. J Bone Joint Surg Am. 1996; 78: 288-298.

6. Naresh K, Murthy N and Veliath AJ. Disseminated Tuberculosis. Ind. J. Surg 1996; 34 (8): 494-96.

7. Sato T, Mori M, Inamatsu T, Watanabe J. Isolated tuberculous appendicular lump. Nippon ronnen-igakkai zasshi, 1992; 29(4): 305-11.

8. Adil A, Chikhaoui N, Ousehal A, Kadiri R. Splenic tuberculosis: Apropos of 12 cases. Ann Radiol Paris 1995; 38 (7-8): 403-7.

9. Sastry SC, Seethapathi Rao VN, Reddy DM . Tuberculosis of appendix. Ind J Tub 1981; 28: 29.

10. Bobrow ML. Friedman S Tuberculosis appendicitis. Am J Surg 1956; 91: 389 . 